\title{
ASPECTS OF THE MANAGEMENT OF NEGOTIATING CLASS II MATERIAL RESOURCES FOR THE BULGARIAN ARMED FORCES UNDER THE CONDITIONS OF RESOURCE LIMITATIONS
}

\author{
Sevdalina DIMITROVA, Donika SHOPOVA \\ "Vasil Levski" National Military University, Veliko Tarnovo, Bulgaria \\ sevdalinaid_bg@mail.bg; kimba1981@abv.bg
}

\begin{abstract}
In an environment of rapid change, accompanied by unpredictable risks and permanent deficit, logistic support authorities are facing many challenges. The wide scope of logistic support necessitates a differentiated management approach to the specific areas of integrated logistics. Since the units are often faced with the need for quick action on the deployment of forces with the necessary equipment at the right time and at the right place, aiming at the same time to achieve mobility, initiative, simplicity, responsibility and flexibility of management of material resources in the search for effective approaches towards that, our scientific interests are focused on the management of negotiating class II material resources in compliance with the dependency "cost-effects."
\end{abstract}

Keywords: defence resource management; management of negotiation; management of material resources.

\section{Introduction}

The complex and controversial security environment necessitates and stresses the role of the accelerated transformation of the Armed Forces and the adaptation of material resources to the parameters of the changing environment. Ensuring security today suggests the presence of armed forces that are able to move quickly over long distances for extended periods of time, equally successful in operations of high intensity or logistic operations. One of the basic principles for improving the efficiency of material resources is the improvement of logistics as a process and structures for the management of inventory. Maintaining a stable level of defence expenditure as a proportion of the gross domestic product is the basis for building the necessary defence capabilities. This directed our research towards the problems of management of negotiating class II material resources for the Bulgarian Armed Forces (BA) in an environment of dynamic changes in the strategic security environment and consistent budget deficit.

\section{The relationship between logistics and resource management}

Based on the systematic approach as a set of defined phases with specified functions and tasks, the research is aimed at the logistics system of the Armed Forces (BC) and the Bulgarian Army and their transformation to the new security environment. Accordingly, the logistics is seen as "one of the most serious challenges in the adaptation of the armed forces to the requirements of modern expeditionary operations and transformation of the logistics system to an integrated, mobile, unified, both for peace and for wartime, system for logistics support of the armed forces adequate to the structure, missions 
and tasks of the troops and forces capable of effective and efficient use of material resources for defence" [1].

In order to meet these challenges, certain requirements are imposed on the $\mathrm{BAF}$ logistics system that aim to ensure the following:

$\checkmark$ high mobility of troops and forces during their deployment;

$\checkmark$ economical, effective and efficient logistic support in response to the priority to achieve the required security and defence capabilities under the conditions of deficit as a real manifestation of the correlation "resources - capabilities";

$\checkmark$ autonomy of logistic units and ongoing operations;

$\checkmark$ compatibility with coalition and allied troops[7,9]

The success of the transformation of the logistics system of the Bulgarian Armed Forces, consistent with their missions and tasks under the conditions of resource deficit and the new security environment is dependent on the principles of continuous support, expedition, multinationality, unity of logistic approaches, and collective responsibility in the implementation of expeditionary operations. The concrete manifestation of these principles is the achievement of "responsibility, powers, priority of operational requirements, cooperation and trust, coordination, provision, sufficiency, efficiency, flexibility, awareness and transparency, simplicity and multinationality" [5] of logistic activities.

Adapting the armed forces and the Bulgarian Army to standards compatible with the modern requirements brings new light upon the principle of effectiveness of the logistics system of the armed forces. An expression of this is the reduction of costs and the efficient provision of troops by the formation of new structures. Accordingly, the main objective of the actions of the armed forces and the Bulgarian Army in peacetime is the creation and rational use of combat potential, the achievement of which depends on the so-called " substitution coefficient " (tradeoff), [10] which is reflected in the construction of small in size, but well-armed and combat-ready armed forces. Their effectiveness is directly dependent on the economic planning assumptions, including the plan for supplying, warehousing, and distribution of material resources. All of the above, together with the management of economic processes in the country and the economic inefficiency of the security and defence structures, in all cases lead to loss of state substance. [2].

The efficient and effective logistic support of military forces and troops in operations is carried out through planning, coordination and synchronization of the procedures in the individual areas through close interaction between the logistics bodies built on the three levels of the system of command and control of the armed forces - strategic, operational and tactical - based on an integrated approach to planning and spending of material resources. And if logistic support at the strategic and operational levels is focused on core activities associated with strategic mobility and joint logistics, the efforts at the tactical level focus on providing individual units. All this is in order to maintain and develop capabilities for accomplishing the tasks of logistic support of the armed forces under the three missions of the armed forces defence, support of international peace and security, and contribution to national security in peacetime [6].

The practical implementation of logistic support activities under the three missions of the armed forces is in direct proportion to their financial support on the basis of the Unified financial plan for material and technical support of the Ministry of Defence. It is the basis for carrying out the financial commitment of supplies and services for the provision of operations in line with the assessment and priorities thereof. For this purpose, the requirements of the financial management system, the doctrine of financial support of $\mathrm{MoD}$, budget guidelines 
for budget spending are to be complied with. [3]

Following the logic of processes, the observations and analyses suggest the critical points of the planning, delivery and distribution of material resources, which are grouped in the following areas:

$\checkmark$ accurate and prioritized definition of the needs in coordination with the availability of necessary financial resources;

$\checkmark$ setting deadlines for delivery in line with the deadlines for completion and readiness of military units;

$\checkmark$ timely order for development of the technical specifications for supplies and services (TS under the Public Procurement Act (PPA)) or initial assignment for development of tactical and technical tasks (TTT) consistent with the technical requirements for life cycle management of defence products;

$\checkmark$ timely planning of supplies and services, consistent with the technological time necessary for the procedure for awarding the procurement contract;

$\checkmark$ preparation and submission of the request for supplies and services;

$\checkmark$ not allowing changes of the parameters of the procedures for procurement that have already been started;

$\checkmark$ precise distribution of quantities and designation of the places of delivery in the contracts for supply of excisable goods;

$\checkmark$ timely commencement and completion of the procedures for public procurement and contracts for supplies;

$\checkmark$ timely acceptance of delivered material resources in accordance with contract requirements, internal rules and accounting documents;

$\checkmark$ exercising effective control on the quality of the delivered material resources at the moment of delivery, subsequent to delivery and others [3].

As a response to all this comes the defence acquisition system (DAS), which is a complex, organizationally structured economic system consisting of interrelated elements in a process of management of material resources and accompanying information flows, where the tasks for the operation of these elements are united by the internal strategic objectives and the impact of a number of external factors. Embracing the logistics approach to the organization of the acquisition system in the Bulgarian Army allows not only to outline the key areas of the acquisition policy, but also to manage the acquisition activities in their entirety. This is the system that answers the question of how to achieve these capabilities through compliance to technology and resources availability; it is the connecting link in the correlation "resources - capabilities".

DAS encompasses the processes of planning, designing, developing, testing, contracting, procurement, manufacturing, deployment (implementation), integrated logistics support and removal from service of defence products. Its scope includes activities providing solutions for selecting the option for meeting the needs of defence capabilities and real resource provisions. Within DAS, planning concerns materiel supply and the necessary integration of newly acquired capabilities of the armed forces as an expression of the life cycle phases of defence products and military infrastructure. This defines the process of DAS, resulting in the creation of the following products: [3]

$\checkmark$ strategy for defence acquisition that, as a vision for the development of defence capabilities of the armed forces in accordance with the potential of defence technology, defence industry, and the economic potential of the country, is the basis for successful implementation of other products. This is what determines how and through what approaches to create lasting value of the armed forces and the Bulgarian Army, corresponding to taxpayers' interests;

$\checkmark$ proposals on the acquisition for research and development (R \& D) and new products, for material resources and services, for construction and construction services, for the removal 
from service. They are the basis of longterm logistic support in line with the preliminary guidance on programming and planned actions in the preliminary plan for the integration of the armed forces. In accordance with the approved proposals, the acquisition requirements in the program memorandum are defined as follows;

$\checkmark$ technically defined supply plans, administrative and legal actions related to the preparation of contract documents for the acquisition of material resources, services and infrastructure. In particular, these are plans for providing medical sevices, medium-term plans for materiel, medium-term plans for development and construction services. They are the basis for carrying out the supply procedures under PPA. Compliance with the above will ensure the real connection between the supply processes and the available resources;

$\checkmark$ plans for disposal of defence products whose development is linked to the drafting of lists of products to removal from service, exploitation of surplus defense products subject to discard and destruction. An integral part of these plans are the estimates of resources required for the organization and implementation of disposal activities.

The above principle model for the management of negotiating material resources for the Bulgarian Army is applied when defining the characteristics of these resources, categorized into a five-class system of identification of supply classes in the Bulgarian Army, consistent with the NATO system. And if for some of the material resources in the different classes a number of publications is available, the impression is that the management of class II material resources rather lacks not only reasonable legislation that reflects the dynamic changes in the security environment, but also profound and practically feasible research papers reflecting the status and issues relating to the opportunities for improving the efficiency of the material resources management. This is the direction of our further reasoning.

\section{Peculiarities of the management of class II material resources for the Bulgarian Army}

Class II material resources include supplies whose volume depends on the size of the organization and equipment, such as clothing (apparel), special equipment and property, armament, equipment, tools, spare parts, transport equipment, camping equipment and others. The diverse nature of the resources in this class, although united under a certain feature, requires the application of a specific approach to their management.

Our research is focused on the activities for the selection and supply of material property, in a particular - camping equipment for the Bulgarian Army, the impact of the transition to professional armed forces over the selection of camping equipment under the conditions of a developing market economy and defining the guidelines for the development of these processes in terms of materiel supply. Moreover, in the dynamic changes of the security environment which are of increasingly unpredictable character, it is a fundamental requirement to concentrate the allied efforts for the establishment and development of expeditionary forces that can be deployed quickly and effectively enough, as for some threats we practically have "zero time warning". Hence, the challenge for Bulgaria, as a member of the Euro-Atlantic structures, determines the need for adequate for the purpose of professionalization of the armed forces supply and storage of materiel supply, and field camping equipment in particular.

Materiel supplies - the materials and equipment - depending on the specific requirements and conditions for storage, are divided into groups as follows: wool and fabrics mixed with chemical fiber, fur items; cotton, flax, hemp, and fabrics mixed with chemical fiber; tents, tarpaulins and 
metal products; leather materials and products; paper - all types, templates and documents; sports equipment; paint, grease, soap and detergents; naphthalene; engineering and technical equipment of the quartermaster service. [4] It is in accordance with this division that the specific conditions for their preservation are set in strict compliance with the "Regulation for storage of property, materials and equipment in warehouses for materiel in the Bulgarian army," the orders, instructions and other guideline documents of the quartermaster service. This itself implies knowledge of the characteristics of the different nomenclatures of different types class II material resources used in the Bulgarian Army. Accordingly, the requirement for storing in terms of temperature regime, light, ventilation, and etc. are defined.

Of no less importance for the effective management of material resources from the researched class is the road routing of deliveries, which is directly dependent on the actual existing road network which is used for transporting that particular type of nomenclatures. On the basis of specific estimates for a particular deployment of a field camp of a certain strength and needs of UME tents and their variety, without going into controversy for the requirements of a field camp with the prescribedother material resources and set level of basic material usage per 100 kilometers in liters for a certain type of vehicles and their modification along a normal road and the distance of a particular route, it becomes possible to determine the required number of vehicles and calculate the cost for transportation and deploying that kind of field camp equipment.

These estimates were also calculated for the use of American tent DRASH 2XB SHELTE or the French military tent Utilis TM36 as material resources for the field camp equipment that have reduced volume, weight and pieces of packaging, which leads to the reduction of the number of used vehicles, significant fuel savings and, hence, financial resource savings that are to be redirected to other activities. It should be noted that the fuel saving is achieved only upon delivery of one item of material equipment that was used in the described estimate procedure. Very important is the role in these processes efficient management of human resources [8].

Based on the conducted research, albeit fragmented due to the limited volume of this publication, the "cost-effects" analysis defines the possibilities for rationalizing the management decisions for effective management of materiel supply for the armed forces.

\section{Conclusion}

Best practices for the use of material resources regarding materiel supply and, in particular, field camp equipment, and more specifically - military tents of up to medium size, support the assertion that effective management of class II material resources for the armed forces is directly dependent on innovation in terms of fabrics and metal structures, resulting in a reduction of the total weight of the tents. This, in turn, contributes to reduced resources for transport and time needed for setting up the camp, which has resulted in the reduction of personnel who could be assigned other activities directly related to the combat readiness and combat power of the armed forces. This is to support the economical, efficient and effective use of defence resources under the dependence "costs-effects."

This publication does not aim to impose a particular choice, but to enable decision makers to make their own choice by providing them science-based alternatives for improving the organization of materiel supply according to the NATO standards and requirements, the participation of our professional armed forces in operations outside the country and for generating defence capabilities. 


\section{References}

[1] White paper on the defence and armed forces of the Republic of Bulgaria, pp.6,12,1, 39$407 \mathrm{http}: / /$ www.md.government.bg/bg/doc/20101130_WP_BG.pdf.

[2] Dimitrova S., Ddefence Resources Management in the Security Sector, Veliko Tarnovo, Vasil Levski National Military University Publishing, 2011, pp. 144-150.

[3] Dimitrova, Resource Management in the Dinamically Changing Security Environment, Ruse, Primax Publishing, 2014, pp.238-241.

[4] Instructions for storing property, materials and equipment in the materiel supply warehouses of the Bulgarian Army, Sofia, 1997.

[5] Logistics Doctrine of the Bulgarian Forces, (HП-4), Order of the Minister of Defence of the Republic of Bulgaria No OX-191 of 08.08.2013, Sofia, pp. 7-11.

[6] Mihaylov, Z., The challenges facing the logistics system for ensuring the implementation of the three missions of the armed forces. Briefing delivered at the methodological meeting of the Director of Logistics Directorate, Varna, 3-4 April, 2013.

[7] National Security Strategy of the Republic of Bulgaria, SG, issue 19, 8 March, 2011, pp. 3-5.

[8] Nenkov N. Buzko, Y Dyachenko, M Petrova, N Nenkov, D Tuleninova, K Koeva. Artificial Intelligence Technologies in Human Resource Development (On-line: www.cmnt.lv), ISSN 1407-5806, ISSN 1407-5814, Transport and Telecommunication Institute, Riga, Latvia, 2016, 20(2) 26-29.

[9] Programme for the Development of the Defence Capabilities of the Bulgarian Armed Forces 2020, Sofia, 2015, pp. 4-6, https://www.md.government.bg/bg/doc/ strategicheski/20151207_Programa_razvitie_otbranit\%20sposobnosti.pdf.

[10] Stankevich, V., J. Gerber, One of the Founders of German Armed Forces Microeconomics. S., Economy University Publishing, 1998, pp. 43,85,98, 101, 178. 